Tersedia online di:http://ejournal-balitbang.kkp.go.id/index.php/jkpi
e-mail:jkpi.puslitbangkan@gmail.com
JURNAL KEBIJAKANPERIKANANINDONESIA
Volume 11 Nomor 2 November 2019
p-ISSN: 1979-6366
e-ISSN: 2502-6550
Nomor Akreditasi Kementerian RISTEKDIKTI: 21/E/KPT/2018

\title{
ANALISIS TINDAKAN SOSIAL DALAM PEMBANGUNAN SENTRA KELAUTAN DAN PERIKANAN TERPADU DI SABANG
}

\section{ANALYSIS OF SOCIAL ACTIONS TO SUPPORT THE DEVELOPMENT SABANG INTEGRATED MARINE AND FISHERIES CENTER}

\author{
Armen Zulham¹, Rani Hafsaridewi' ${ }^{*}$ Freshty Yulia Arthatani ${ }^{1}$ dan Mira ${ }^{1}$ \\ 'Balai Besar Riset Sosial Ekonomi Kelautan dan Perikanan, Gedung BRSDM KP I, Ancol Timur, Jakarta Utara-14430, Indonesia \\ Teregistrasi I tanggal: 06 Mei 2019; Diterima setelah perbaikan tanggal: 23 Januari 2020; \\ Disetujui terbit tanggal: 28 Januari 2020
}

\begin{abstract}
ABSTRAK
Tindakan sosial adalah perilaku pelaku usaha perikanan terhadap pelaku lain dengan tujuan dan motivasi tertentu. Permasalahannya, tindakan sosial pelaku usaha pada kawasan Sentra Kelautan dan Perikanan Terpadu (SKPT) Sabang tidak responsif mendukung beroperasinya SKPT Sabang. Tujuan tulisan ini mempelajari karakteristik aspek sosial budaya masyarakat perikanan Sabang serta tindakan sosial yang terkait dengan hal itu agar SKPT Sabang dapat berfungsi. Data dan informasi diperoleh dari Focus Group Discussion (FGD). Observasi langsung (aktuelles verstehen), dan pemahaman motif tindakan (eklarendes verstehen) digunakan sebagai teknik untuk mendalami infomasi hasil FGD tersebut. Pengumpulan data dilakukan pada Oktober 2018. Hasil penelitian ini menunjukkan: tindakan sosial tradisional mendominasi keputusan pelaku usaha dalam penangkapan ikan. Pelaku usaha perikanan tersebut harus taat hukum adat laot yang dipantau Panglima Laot; tindakan sosial rasional instrumental mendominasi tindakan pelaku usaha pada kegiatan penanganan hasil tangkapan serta distribusi dan pemasaran ikan. Motif tindakan sosial yang terakhir ini mempengaruhi pelaku usaha lain, agar pasokan ikan dapat diperoleh atau mengoptimalkan manfaat karena tindakan pelaku usaha lain. Tulisan ini merekomendasikan agar di SKPT Sabang dilakukan perubahan sosial melalui transformasi 30\%-40\% dari 684 unit armada perikanan <3 GT (Gross Ton) menjadi armada >10 GT. Transformasi ini akan mendorong tindakan sosial pada trip penangkapan ikan, peningkatan permintaan tenaga kerja trampil (pawang) dan penggunaan teknologi dalam penanganan serta pemasaran/distribusi ikan.
\end{abstract}

\section{Kata Kunci: Perikanan laut; perairan Sabang; tindakan sosial; aspek sosial budaya}

\section{ABSTRACT}

Social action is defined as the action among business actors for specific purposes or motives. The problem of social action in the SKPT (integrated marine and fisheries center) Sabang is that the business actors in fisheries are not responsive to support the operationalization of SKPT Sabang. The purpose of this paper is to learn the characteristics of business actors on sociocultural aspects and social action to support the daily operation of SKPT Sabang. Data and information were collected from the Focus Group Discussion (FGD). Direct observation (aktuelles verstehen) and Empathetic Understanding (eklarendes verstehen) were used as techniques to collect advanced information. Data were collected in October 2018. The research findings are: traditional social actions dominate fishing actors' activities. The business actors remain to obey on the local traditional rule (adat laot rule) observed by Panglima Laot; instrumental rational social actions are always carried out by business actors on the post-harvest fishing activities as well as distribution and fish marketing. The last social action motives are to influence others to provide fish and to reach optimal benefit due to other business actor action. This paper recommends preparing the social change through transformation $30 \%-40 \%$ of $<3$ GT fishing vessel to $>10$ GT in Sabang. 
It will then change the duration of fishing activity, increase demand for skilled labor (pawang), and the application of technology in post-harvest as well as marketing/fish distribution.

\section{Keywords: Marine fisheries; Sabang; social action; socio cultural aspect}

\section{PENDAHULUAN}

Pada dokumen resmi, Sentra Kelautan dan Perikanan Terpadu, merupakan strategi Kementerian Kelautan dan Perikanan dalam mendukung percepatan pelaksanaan pembangunan di pulau-pulau kecil dan kawasan perbatasan (Kepmen KP No. 51/ KEPMEN-KP/2016). Strategi pembangunan itu merupakan konstruksi sosial (Berger \& Luckmann, 1991). Konstruksi sosial dalam pembangunan perikanan menurut pemikiran Berger \& Luckmann (1991) terkait dengan kebijakan, aturan/norma dan organisasi, sehingga merupakan strategi untuk mewujudkan tujuan pembangunan perekonomian.

Konstruksi sosial pada SKPT Sabang (Kepmen KP No. 51/KEPMEN-KP/2016) adalah kebijakan pembangunan ekonomi pulau kecil dan terluar dengan membangun infrastruktur perikanan, pemanfaatan potensi ikan, penguatan kelembagaan pengelola serta pengembangan ekonomi dan bisnis yang terintegrasi pada SKPT itu. Telaah teknis pembangunan pada SKPT Sabang sudah dilakukan (Ditjen Perikanan Budidaya, 2016), namun telaah sosial (tindakan sosial) belum ditindaklanjuti. Telaah sosial diperlukan untuk mengetahui perilaku pelaku usaha terhadap pelaku atau kelompok lain dengan motif dan tujuan tertentu. Hasil telaahan sosial seperti pada tulisan Pinker (1998); Jones et al. (2016); dan Riss (2016) dapat menjadi acuan dalam menyusun strategi memfungsikan SKPT Sabang.

Tindakan sosial pelaku usaha (nelayan dan pedagang) di Sabang dipelajari pada aspek sosial budaya, meliputi: budaya menangkap ikan, status sosial, peran sosial, kelompok sosial, intitusi sosial. Aspek tersebut menentukan berfungsinya SKPT Sabang (Ferris et al., 2010; Mooney et al., 2000). Sebagai contoh tindakan sosial peningkatan produktivitas melalui adopsi teknologi yang dipelajari Matuschke (2008) berhasil mendorong pelaku usaha mengadopsi teknologi, setelah kelompok sosial dalam masyarakat itu mendapat advokasi dari penyuluh. Pada tindakan sosial tersebut interaksi sosial, penyuluh ikut berperan sehingga adopsi teknologi dapat diwujudkan (Samuels, 1995; Hodgson, 1998). Pemahaman tentang tindakan sosial digunakan luas dalam proses pembangunan misalnya di Thailand dimanfaatkan untuk mendukung pelaksanaan program perbaikan ekonomi bagi suku pedalaman (Jackie et al., 2018), di Australia dan Selandia Baru dikembangkan untuk mempercepat adaptasi sektor konstruksi terhadap perubahan sosial dan bisnis dalam perekonomian negara tersebut (Lim \& Loosemore, 2016).

Fenomena sosial di atas belum dipertimbangkan pada SKPT Sabang, sehingga partisipasi pelaku usaha terhadap SKPT itu belum mencapai tingkat partisipasi mandiri sebagaimana dimaksud oleh Pretty (1995). Tingkat partisipasi mandiri terwujud jika tindakan sosial pelaku usaha mampu beradaptasi dengan fungsi SKPT Sabang, memiliki tujuan yang sama dengan SKPT, ada target integrasi, dan punya kemampuan menjaga pola relasi yang disepakati (Martono, 2014; Parsons, 1951; Johnson, 1994; Poloma, 2007).

Budaya mendaratkan ikan pada berbagai lokasi merupakan tindakan sosial yang didorong pedagang (toke bangku) di Sabang untuk kepentingan mendapat dan mengendalikan pasokan ikan ke pasar. Pada tindakan sosial itu, terdapat kekuasaan yang mempengaruhi nelayan (Priya, 2013; Oyedokun, 2016) dan berpotensi kurang mendukung program SKPT, serta peluang menimbulkan unreported fishing dan unregulated fishing cukup besar, karena pasokan ikan yang dilaporkan tidak sesuai dengan yang diperoleh (Zulham et al., 2017; Zulham, 2018).

Oleh sebab itu, tujuan tulisan ini adalah mempelajari karakteristik aspek sosial budaya dan tindakan sosial pelaku usaha perikanan di Sabang pada sistem produksi, penanganan hasil serta distribusi dan pemasaran, agar SKPT Sabang dapat berfungsi.

Data dan informasi dikumpulkan pada Oktober 2018 di Kota Sabang. Data primer dikumpulkan melalui Focus Group Discussion (FGD), observasi langsung (aktuelles verstehen) tindakan dan ekspresi pelaku usaha, serta memahami motif pelaku usaha (eklarendes verstehen). Data sekunder dari publikasi resmi Dinas Perikanan Kota Sabang dan Badan Pusat Statistik (BPS) Kota Sabang. Analisis deskriptif (menganalisis fakta/relasi di lapangan) dan preskriptif (mengembangkan fakta/relasi menjadi strategi untuk tujuan tertentu) digunakan untuk memahami motif, pola relasi dan efisiensi tindakan sosial pelaku usaha (Huisman, 2015; de Lange, 2017; Heaney, 2015). 


\section{TINDAKAN SOSIAL DAN ASPEK SOSIAL BUDAYA}

Tindakan sosial diklasifikasi Weber (1964) dalam 4 tipe, yaitu: (a) tindakan sosial tradisional, didasarkan pada kebiasaan; (b) tindakan sosial afektif, berdasarkan emosi/perasaan; (c) tindakan sosial rasionalitas nilai, yang dilakukan berdasarkan kepercayaan; (d) tindakan sosial rasionalitas instrumental - purposfull rational dilakukan dengan perhitungan/tujuan tertentu. Tindakan sosial tersebut dipelajari pada kegiatan penangkapan ikan, penanganan ikan hasil tangkapan serta distribusi dan pemasaran hasil tangkapan.

Secara umum, motif tindakan sosial pemanfaatan sumber daya perikanan di perairan Sabang (Wilayah Pengelolaan Perikanan Republik Indonesia (WPP-NRI 571 dan WPP-NRI 572) adalah mulai dari harus ikut aturan adat setempat sampai pada motif ekonomi, agar ikan mudah didapat untuk memenuhi permintaan pasar. Besarnya motif tersebut, didorong oleh ketersediaan ikan pelagis besar, ikan pelagis kecil, ikan karang dan ikan demersal yang dapat dieksploitasi pada perairan Sabang (Kepmen KP No. 50/KEPMEN-KP/2017). Pada master plan SKPT Sabang, estimasi jumlah ikan yang boleh ditangkap pada perairan Sabang tahun 2016 adalah 25.084 ton (Ditjen Perencanaan Ruang Laut, 2017). Sementara, BPS Kota Sabang, (2018) melaporkan hasil tangkapan perikanan laut di Sabang tahun 2013 (3.322 ton), 2015 (3.867 ton) dan tahun 2016 (4.747 ton). Hasil tangkapan pada tahun 2016 tersebut setara dengan $18,92 \%$ dari jumlah (volume) ikan yang boleh ditangkap (JTB). Rendahnya kemampuan produksi ikan tersebut terkait dengan tindakan sosial pelaku usaha perikanan Sabang.

Armada perikanan di Sabang umumnya melakukan trip harian untuk menangkap ikan (one day fishing) dan tidak melaut pada hari Jumát dan beberapa hari libur nasional (Anonim, 1992). Budaya melaut tersebut telah terpola dalam kehidupan nelayan Sabang, dan menurut Sanderson (2010) berpengaruh pada rendahnya kemampuan produksi perikanan. Budaya melaut one day fishing nelayan Sabang tidak berbeda dengan nelayan di Kepulauan Nicobar sekitar $190 \mathrm{Km}$ dari Sabang. Nelayan Sabang menggunakan teknologi penangkapan ikan yang lebih baik dari nelayan Kepulauan Nicobar, karena nelayan Sabang telah berorientasi pasar, teknologi penangkapan ikan diperkenalkan pedagang dari luar daerah, sementara nelayan Kepulauan Nicobar lebih subsisten dan cenderung menggunakan teknologi tradisional, karena pasar terbatas. Tindakan sosial nelayan penangkap ikan pada dua lokasi adalah tindakan sosial tradisional, yang tetap mengikuti kebiasaan setempat
(Ravikumar et al., 2015; Ravikumar et al., 2016). Di daerah Manyar Kabupaten Gresik tindakan sosial tradisional dan tindakan sosial rasional instrumental dijadikan acuan menyusun strategi perbaikan kehidupan sosial ekonomi masyarakat pada kawasan pertambakan, akibat alih fungsi lahan karena pembangunan infrastruktur pada kawasan tersebut (Rohmaida \& Utami, 2016). Pada sisi lain Supraja (2012), melihat 4 tindakan sosial Weber di atas tidak jelas dalam perbaikan kehidupan sosial ekonomi masyarakat, karena mengabaikan peran waktu di dalamnya. Mengikuti pemikiran Schutz, Supraja (2012) menjelaskan dalam memperbaiki kehidupan sosial ekonomi masyarakat tindakan sosial itu di dalamnya terdapat durasi yang membatasi tujuan perbaikan kehidupan sosial ekonomi tersebut. Tindakan sosial tersebut tidak tersegmentasi dalam 4 tindakan sosial seperti yang disebutkan di atas.

Kontribusi pembiayaan oleh pelaku usaha pada penangkapan ikan di Sabang menurut konsep Budowski \& Tillmann (2013), membentuk stratifikasi sosial yang terdiri dari: pemilik kapal, "pawang" (nahkoda) dan Anak Buah Kapal (ABK). Selain itu dalam bisnis perikanan terdapat toke bangku dan panglima laot. Stratifikasi tersebut, seperti pemikiran Wyatt-Nichol et al. (2011) menjadi penggerak sosial ekonomi masyarakat perikanan Sabang. "Panglima laot" adalah status sosial yang diberikan pada tokoh dalam lembaga adat laot yang memantau aktivitas pawang dan ABK di laut serta aktivitas bisnis ikan toke bangku di Sabang, sehingga berfungsi mengendalikan konflik sosial. Toke bangku adalah penyedia modal, dan social safety fund untuk keluarga nelayan sehingga berfungsi melindungi kehidupan ekonomi nelayan.

Pada status sosial pelaku usaha di atas terdapat kewajiban (obligation) dan harapan yang disebut sebagai peran sosial. Peran sosial tesebut merupakan bentuk pelaksanaan hak, kewajiban, tugas, atau tanggung jawab pelaku usaha sesuai dengan status sosialnya. Toke bangku jika tidak dapat memberi modal maka status sosialnya diragukan masyarakat dan perannya akan jadi mugee engkot (pedagang ikan keliling). Adakalanya peran sosial panglima laot dan toke bangku tidak sesuai kewajiban, terutama ketika harus membebaskan nelayan Sabang yang ditangkap otoritas perairan kepulauan Andaman dan Nicobar (India). Peran panglima laot dan toke bangku yang demikian adalah peran kemanusiaan yang sering dilakukan oleh panglima laot terdahulu. Toke bangku yang berbisnis ikan memiliki jaringan sosial pemasok ikan dan penjual ikan. Jaringan sosial tersebut membentuk social group yang terpisah dan "diikat" dengan uang/ 
modal. Sosial group tersebut dibentuk untuk menguasai pasar.

Intitusi sosial di atas adalah pelaksana aturan/ norma dalam masyarakat, yang berfungsi mengendalikan konflik antar pelaku usaha pada struktur sosial di Sabang. Institusi sosial pada struktur sosial di Sabang dibentuk berdasarkan kesepakatan untuk mengatur interaksi saat penangkapan ikan, cara pembayaran, serta cara berbisnis.

\section{TINDAKAN SOSIAL PADA SISTEM PRODUKSI PERIKANAN}

Tabel 1, memberi informasi karakteristik sosial budaya dan tipe tindakan sosial pada sistem produksi perikanan di Sabang, 2018. Aspek budaya pada Tabel 1, menunjukkan kegiatan penangkapan ikan di Sabang merupakan aktivitas penangkapan ikan harian (one day fishing), sumber modal kegiatan menggunakan modal sendiri atau modal dari toke bangku (meminjam uang dari bank tidak lazim beberapa nelayan mengatakan riba) dan bagi hasil mengikuti aturan adat laot. Tindakan sosial nelayan Sabang dari aspek budaya merupakan tindakan sosial tradisional (traditional social action), motifnya mengikuti tradisi atau kebiasaan setempat, mengabaikan kebiasaan tersebut akan mendapat sanksi sosial (Thomson, 2017; Trueman, 2015). Kebiasaan melaut one day fishing menyebabkan produktivitas hasil tangkapan nelayan Sabang rendah dan tidak economic of scale. Dengan hasil tangkapan yang sedikit, nelayan Sabang memilih mendaratkan ikan pada pantai di desa mereka (karena terdapat pedagang yang pasti membeli hasil tangkapan, serta dapat menyediakan BBM (Bahan Bakar Minyak) untuk menangkap ikan) dibandingkan dengan di SKPT (fasilitas BBM belum tersedia dan pedagang belum ada). Tindakan sosial nelayan Sabang yang demikian menghalangi berfungsinya SKPT Sabang.

Tabel 1. Karakteristik sosial budaya dan tipe tindakan sosial pada sistem penangkapan ikan di Sabang, 2018

Table 1. Social culture characteristics and type of social action in fishing system in Sabang, 2018

\begin{tabular}{|c|c|c|c|c|}
\hline $\begin{array}{l}\text { Aspek Sosial } \\
\text { Budaya / Socio } \\
\text { cultural aspects }\end{array}$ & $\begin{array}{l}\text { Penangkapan } \\
\text { ikan /fishing }\end{array}$ & $\begin{array}{c}\text { Sumber } \\
\text { pembiayaan / } \\
\text { source of } \\
\text { financing }\end{array}$ & $\begin{array}{l}\text { Sistem bagi hasil / } \\
\text { profit sharing } \\
\text { system }\end{array}$ & $\begin{array}{c}\text { Tipe } \\
\text { tindakan } \\
\text { sosial }^{1} / \\
\text { type of } \\
\text { social } \\
\text { Action }^{1} \\
\end{array}$ \\
\hline Budaya / culture & $\begin{array}{l}\text { Aktivitas one day } \\
\text { fishing. }\end{array}$ & $\begin{array}{l}\text { dana sendiri atau } \\
\text { toke bangku }\end{array}$ & $\begin{array}{l}\text { Mengikuti hukum } \\
\text { adat laot }\end{array}$ & Tradisional \\
\hline $\begin{array}{l}\text { Status sosial / } \\
\text { social status }\end{array}$ & Dominasi pawang & $\begin{array}{c}\text { Dominasi toke } \\
\text { bangku }\end{array}$ & $\begin{array}{c}\text { Dominasi panglima } \\
\text { laot }\end{array}$ & Tradisional \\
\hline $\begin{array}{l}\text { Kelompok Sosial / } \\
\text { social group }\end{array}$ & $\begin{array}{c}\text { Mengikuti toke } \\
\text { bangku }\end{array}$ & Toke bangku & $\begin{array}{c}\text { Mengikuti toke } \\
\text { bangku }\end{array}$ & $\begin{array}{l}\text { Rasionalitas } \\
\text { instrumental }\end{array}$ \\
\hline $\begin{array}{l}\text { Peran sosial / } \\
\text { social role }\end{array}$ & $\begin{array}{c}\text { Pawang \& toke } \\
\text { bangku }\end{array}$ & Toke bangku & Panglima laot & $\begin{array}{l}\text { Rasionalitas } \\
\text { instrumental }\end{array}$ \\
\hline $\begin{array}{l}\text { Institusi sosial / } \\
\text { social institution }\end{array}$ & $\begin{array}{c}\text { Diatur dalam } \\
\text { hukum adat laot }\end{array}$ & $\begin{array}{c}\text { Diatur dalam } \\
\text { hukum adat laot }\end{array}$ & $\begin{array}{l}\text { Diatur dalam hukum } \\
\text { adat laot }\end{array}$ & Tradisional \\
\hline
\end{tabular}
Sumber : FGD (Oktober, 2018)/source: FGD discussion (October, 2018).

Keterangan: 1). Tindakan sosial menurut klasifikasi Weber (1964) / Remark: ")Social action based on Weber (1964) classification.

Pada sistem produksi, status sosial pelaku usaha dalam masyarakat perikanan Sabang adalah unik. Pawang (nahkoda) merupakan leader yang diberi kekuasaan oleh pemilik kapal dalam penangkapan ikan, toke bangku merupakan sumber modal utama dalam sistem produksi perikanan dan Panglima laot adalah tokoh yang mengatur berbagai aktivitas di laut dan perolehan hasil laut. Tindakan sosial pelaku usaha pada aspek status sosial merupakan tindakan sosial tradisional, motifnya hanya mengikuti kebiasaan sesuai kesepakatan dalam masyarakat perikanan Sabang. Achieved status tersebut harus dilaksanakan, menurut Ferris et al. (2010) status tersebut dapat gugur jika dilaksanakan menyimpang dan tidak sesuai dengan kebiasaan. Status sosial pelaku usaha dapat dimanfaatkan untuk membantu memfungsikan berbagai fasilitas SKPT Sabang dengan mendorong pelaku usaha tersebut berintegrasi dalam SKPT tersebut.

Kelompok sosial (social group) sangat diperlukan dalam sistim produksi perikanan. Kelompok sosial ini dikendalikan oleh toke bangku. Tidakan sosial toke bangku membentuk kelompok sosial merupakan tindakan sosial rasionalitas instrumental, bertujuan untuk mendapat pasokan ikan dari nelayan. Toke 
bangku membangun sosial group melalui ikatan yang disebut Damsar \& Indrayani (2013) sebagai keterlekatan. Keterlekatan itu menurut Granovetter (1985) merupakan tindakan ekonomi yang disituasikan secara sosial melekat dalam jaringan sosial personal yang sedang berlangsung antar pelaku untuk mendapatkan ikan. Keterlekatan dalam jaringan sosial toke bangku dengan pemilik kapal untuk mendapat ikan disebut sebagai keterlekatan kuat (Granovetter, 1995).

Pada sistem produksi perikanan peran sosial didominasi oleh pawang, toke bangku dan panglima laot. Tindakan sosial mereka merupakan tindakan sosial rasionalitas instrumental, dengan motif ekonomi. Peran sosial pawang melaksanakan penangkapan ikan dan mengendalikan konflik agar mendapat banyak hasil tangkapan. Pada saat yang sama, pawang mengoptimalkan manfaat sistim bagi hasil, karena fluktuasi harga ikan dengan menjual sebagian ikan di laut. Toke bangku dengan status sosial yang melekat padanya punya peran sosial melindungi kehidupan ekonomi nelayan, sehingga memperkuat jaringan perolehan pasokan ikan. Panglima laot, berperan menjaga agar keberlanjutan bisnis perikanan pada WPP-NRI 571 dan WPP-NRI 572 dapat terwujud. Pawang, toke bangku dan panglima laotmenganggap keberadaan SKPT Sabang merupakan saingan, karena dianggap mengunakan jaringan sosial yang telah dibangun toke bangku untuk memfungsikan fasilitas yang telah dibangun.

Pada sistem bisnis perikanan di Sabang, terdapat institusi sosial hukum adat laot, yang mengatur dan mengawasi aktivitas bisnis perikanan Sabang. Tindakan sosial pelaku usaha tersebut adalah tindakan sosial tradisional. Dalam institusi hukum adat laot diatur: "toke bangku" mendapatkan 10\% dari hasil kotor, jika modal penangkapan ikan bersumber dari toke bangku. Namun, jika nelayan menggunakan modal sendiri, dan toke bangku diminta untuk menjual hasil tangkapan nelayan, maka toke bangku akan memperoleh 3\% dari hasil kotor penjualan ikan. Kemudian $10 \%$ dari hasil kotor tersebut dikelola nahkoda untuk perbaikan armada penangkapan ikan. Sementara SKPT Sabang dibangun dengan investasi besar dan targetnya menghasilkan ikan dengan volume besar dan mutu premium, sehingga SKPT ini tidak dapat menggunakan instrumen hukum adat laot seperti yang dilakukan masyarakat perikanan Sabang.

\section{TINDAKAN SOSIAL PADA SISTEM PENANGANAN HASIL TANGKAPAN IKAN}

Nelayan Sabang tidak melakukan penanganan hasil tangkapan ikan di atas kapal dan tempat pendaratan. Keputusan itu dilakukan dengan motif memperkecil biaya. Akibatnya kualitas ikan hasil tangkapan tidak seragam. Karakteristik penanganan ikan tersebut dapat dipelajari pada Tabel 2.

Perlakuan nelayan terhadap hasil tangkapan ikan tidak sesuai dengan aturan penanganan yang baik. Budaya penanganan ikan/pembongkaran ikan yang ada sudah terpola sesuai dengan kebiasaan setempat. Ikan hasil tangkapan terutama (tuna dan cakalang) setelah ditangkap hanya diletakkan di lambung kapal/perahu (palka dan es tidak ada). Pembongkaran ikan dilakukan manual, saat dibawa ke tempat pendaratan ikan dimasukkan ke keranjang atau palka yang telah diberi es curah (jika tersedia). Tindakan sosial nelayan merupakan tindakan sosial rasional instrumental, sebagai respon, tidak ada perbedaan harga ikan yang mendapatkan perlakuan penanganan dan tidak.

Pada sistem penanganan hasil tangkapan ikan, status sosial nelayan (pawang) hanya sebagai subordinat toke bangku. Pawang tidak diberi insentif oleh toke bangku, walaupun dia dapat menangkap ikan dalam jumlah banyak. Oleh sebab itu, penanganan ikan di atas kapal dilakukan seadanya oleh pawang. Kekuasaan toke bangku sangat dominan dalam penentuan harga ikan. Posisi ini terjadi karena sistim bagi hasil perikanan dalam institusi sosial hukum adat laot dinilai kurang adil. Bagian yang diterima toke bangku cukup besar. Hal itu menyebabkan, sebelum ikan didaratkan, sebagian ikan dijual di laut kepada nelayan lain atau kapal penangkapan ikan lain oleh pawang tanpa sepengetahuan pemilik kapal. Penjualan ikan di laut, telah merugikan beberapa perusahaan perikanan yang kapalnya dioperasikan oleh nelayan Sabang. Padahal, peran sosial toke bangku dan perusahaan perikanan cukup signifikan dalam pengembangan usaha perikanan dan perekonomian nelayan serta menyediakan lapangan kerja untuk masyarakat setempat. Tindakan sosial yang dilakukan nelayan/pawang merupakan tindakan sosial rasional instrumental, karena perilaku seperti yang diuraikan diatas. 
Tabel2. Karakteristik sosial budaya dan tipe tindakan sosial pada sistim penanganan hasil tangkapan ikan di Sabang, 2018.

Table 2. Social culture charachteristics and social action type on fish handling system in Sabang, 2018

\begin{tabular}{|c|c|c|c|c|}
\hline $\begin{array}{l}\text { Aspek Sosial } \\
\text { Budaya / Socio } \\
\text { cultural aspects }\end{array}$ & $\begin{array}{c}\text { Penanganan } \\
\text { ikan diatas kapal } \\
\text { / fish handling } \\
\text { on board }\end{array}$ & $\begin{array}{c}\text { Pembongkara } \\
\text { n ikan / fish } \\
\text { unloading }\end{array}$ & $\begin{array}{l}\text { Penanganan ikan di } \\
\text { tempat pendaratan } \\
\text { ikan / fish handling at } \\
\text { the landing sites }\end{array}$ & $\begin{array}{l}\text { Tipe tindakan } \\
\text { sosial }{ }^{1} / \text { type } \\
\text { of social } \\
\text { action }^{1}\end{array}$ \\
\hline Budaya / culture & $\begin{array}{l}\text { lambung kapal / } \\
\text { perahu }\end{array}$ & Manual & $\begin{array}{l}\text { Diletakkan dilantai } \\
\text { dalam keranjang }\end{array}$ & $\begin{array}{l}\text { iasional } \\
\text { istrumental }\end{array}$ \\
\hline $\begin{array}{l}\text { Status sosial / } \\
\text { social status }\end{array}$ & $\begin{array}{l}\text { Sub ordinat toke } \\
\text { bangku }\end{array}$ & Buruh angkut & Toke bangku. & $\begin{array}{l}\text { al } \\
\text { ental }\end{array}$ \\
\hline $\begin{array}{l}\text { Kelompok Sosial / } \\
\text { social group }\end{array}$ & $\begin{array}{l}\text { Dibentuk oleh } \\
\text { toke bangku }\end{array}$ & $\begin{array}{l}\text { Dibentuk oleh } \\
\text { toke bangku }\end{array}$ & $\begin{array}{l}\text { Dibe } \\
\text { ban }\end{array}$ & $\begin{array}{l}\text { Rasional } \\
\text { instrumental }\end{array}$ \\
\hline $\begin{array}{l}\text { Peran sosial / } \\
\text { social role }\end{array}$ & $\begin{array}{l}\text { Dominasi toke } \\
\text { bangku }\end{array}$ & $\begin{array}{l}\text { ominasi toke } \\
\text { angku }\end{array}$ & Dominasi toke bangku & ntal \\
\hline $\begin{array}{l}\text { Institusi sosial / } \\
\text { social institution }\end{array}$ & $\begin{array}{l}\text { Aturan positif } \\
\text { tidak diadopsi }\end{array}$ & $\begin{array}{l}\text { Aturan positif } \\
\text { tidak diadopsi }\end{array}$ & $\begin{array}{l}\text { Aturan positif tidak } \\
\text { diadopsi }\end{array}$ & $\begin{array}{l}\text { Rasional } \\
\text { instrumental }\end{array}$ \\
\hline
\end{tabular}

Sumber : Diskusi FGD (Oktober, 2018) / source: FGD discussion (October, 2018).

Keterangan : 1). Tindakan sosial menurut klasifikasi Weber (1964) / Remark: ${ }^{1}$ Social action based on Weber (1964) classification.

Sosial group yang dibangun toke bangku pada perikanan di Sabang bukan bertujuan untuk penanganan ikan hasil tangkapan, tetapi untuk mengumpulkan ikan agar dapat dipasok ke pasar. Akibatnya ikan yang diterima toke bangku mutu dan ukurannya beragam dan paling dominan adalah ikan tongkol (ukuran $1 \mathrm{~kg}$ berkisar antara 3 ekor) dan cakalang ( $3 \mathrm{~kg}$ sampai $5 \mathrm{~kg}$ per ekor). Sementara ikan tuna sirip kuning per perahu jumlahnya terbatas, dalam satu minggu tertangkap antara 1 sampai 2 ekor dengan berat rata-rata $50 \mathrm{~kg}$.

Kegiatan penanganan ikan di atas kapal, bongkar ikan dan penanganan ikan di tempat pendaratan ikan tidak diatur lembaga adat laot. Aturan positif yang dibuat pemerintah tidak diadopsi pelaku usaha perikanan, karena harga yang diperoleh tidak sesuai, menambah biaya, dan ikan hasil tangkapan tanpa perlakukan yang baik tetap diterima pasar. Ikan hasil tangkapan nelayan (terutama tuna sirip kuning) menurut eksportir di Banda Aceh kualitasnya hanya grade C. Satu eksportir tuna ekspor yang berbasis di Banda Aceh, mencoba memperbaiki mutu, dengan menerapkan aturan yang ditetapkan pasar. Tindakan sosial penanganan tuna ini hanya diikuti oleh nelayan penangkap tuna tertentu saja. Nelayan lain masih menerapkan kebiasaan yang lama, sehingga ikan tuna atau cakalang grade $\mathrm{A}$ yang dihasilkan nelayan Sabang jumlahnya sangat terbatas. Tindakan sosial yang dilakukan pelaku usaha adalah tindakan sosial rasional instrumental, karena motif ekonomi.
Rendahnya mutu hasil tangkapan pada nelayan Sabang, menyulitkan toke bangku Sabang menjual ikan hasil tangkapan. Oleh sebab itu toke bangku Sabang melakukan negosiasi dengan toke bangku di Lampulo Banda Aceh. Negosiasi tersebut membentuk koalisi sosial dalam perdagangan ikan, karena daya serap konsumen Kota Sabang rata-rata 3 ton ikan per hari. Koalisi sosial ini membentuk keterlekatan kuat atau keterlekatan lemah. Koalisi sosial, keterlekatan kuat terjadi karena terikat perjanjian. Sebaliknya, koalisi sosial keterlekatan lemah terjadi karena kesepakatan untuk mencari pasar. Pada tahun 2018, koalisi keterlekatan lemah terjadi antara toke bangku Sabang dengan Badan Pengelola Pelabuhan Kawasan Sabang untuk mengekspor ikan nelayan Sabang ke Port Blair (kepulauan Andaman dan Nikobar). Keberlanjutan perdagangan ikan tersebut terkendala pada terbatasnya volume ikan yang untuk ekspor dan harga ikan di Sabang yang tidak stabil.

\section{TINDAKAN SOSIAL PADA SISTEM DISTRIBUSI DAN PEMASARAN IKAN}

Peran toke bangku sangat mendominasi keputusan pengangkutan ikan, jaringan pasar dan transaksi perdagangan ikan di Sabang. Tindakan sosial yang dilakukan adalah tindakan sosial rasionalitas instrumental untuk mendapat harga yang baik. Distribusi dan pemasaran ikan di Sabang telah terpola, antara toke bangku Sabang dengan mitra 
toke bangku di Ulhee CotBanda Aceh. Pengangkutan ikan ke lokasi tersebut menggunakan kapal penangkap ikan. Selanjutnya dimasukkan dalam container ikan berisi es curah dikirim dengan truk ke Belawan.

Ikan tuna kualitas ekspor pola pengirimannya memanfaatkan cargo pesawat ke Kuala Lumpur melalui Bandara Sultan Iskandar Muda di Banda Aceh. Ikan kualitas ekspor dengan tujuan Jepang atau Thailand dikirim melalui Bandara Soekarno Hatta dari Bandara Sultan Iskandar Muda. Sistim pembayaran dalam transaksi ikan pada pasar domestik dan ekspor adalah konsinyasi, pembayaran ikan dilakukan 1-2 minggu setelah ikan diterima pedagang di pasar tujuan. Pembayaran dilakukan melalui bank, dalam mata uang rupiah (pasar domestik) dan dollar Amerika (pasar ekspor).
Pada sistem distribusi dan pemasaran ikan serta transaksi ikan, peran toke bangku sangat penting dalam berbagai keputusan. Kecermatan keputusan tersebut menjadi acuan penting bagi nelayan di Sabang, untuk mendapat harga ikan yang baik tanpa ikut ke pasar tujuan. Toke bangku berperan menentukan alat angkut, jaringan pasar dan transaksi pada pasar domestik.

Sosial group distribusi ikan yang dibangun toke bangku bersifat tertutup dan tidak dapat dimanfaatkan oleh toke bangku atau pedagang lain. Sosial group terdiri dari jaringan sosial yang telah diikat oleh toke bangku. Tindakan sosial rasionalitas instrumental yang demikian dibangun dengan motif mengendalikan pasokan ikan untuk mendapat harga yang baik.

Tabel 3. Karakteristik sosial budaya dan tipe tindakan sosial pada sistim distribusi dan pemasaran ikan di Sabang, 2018

Table 3. Social cultural charachteristics and social action type on fish distribution and marketing in Sabang, 2018

\begin{tabular}{|c|c|c|c|c|}
\hline $\begin{array}{l}\text { Aspek Sosial } \\
\text { Budaya / Socio } \\
\text { cultural aspects }\end{array}$ & $\begin{array}{c}\text { Pengangkutan } \\
\text { ikan / } \\
\begin{array}{c}\text { transportation of } \\
\text { fish }\end{array}\end{array}$ & $\begin{array}{c}\text { Jaringan } \\
\text { pemasaran ikan } \\
\text { / fish marketing } \\
\text { network }\end{array}$ & $\begin{array}{c}\text { Sistim transaksi } \\
\text { perdagangan ikan / } \\
\text { fish trade } \\
\text { transaction system }\end{array}$ & $\begin{array}{c}\text { Tipe } \\
\text { tindakan } \\
\text { sosial }^{1 /} \\
\text { type of } \\
\text { social } \\
\text { action }^{1}\end{array}$ \\
\hline Budaya / culture & $\begin{array}{l}\text { Kapal / perahu } \\
\text { penangkap ikan } \\
\text { dan truk }\end{array}$ & $\begin{array}{l}\text { jaringan toke } \\
\text { bangku }\end{array}$ & $\begin{array}{l}\text { kosinyasi dalam 1- } 2 \\
\text { minggu setelah ikan } \\
\text { diterima. }\end{array}$ & $\begin{array}{l}\text { Rasionalitas } \\
\text { instrumental }\end{array}$ \\
\hline $\begin{array}{l}\text { Status sosial / } \\
\text { social status }\end{array}$ & $\begin{array}{l}\text { Dominasi toke } \\
\text { bangku }\end{array}$ & $\begin{array}{l}\text { Dominasi toke } \\
\text { bangku }\end{array}$ & $\begin{array}{l}\text { Dominasi toke } \\
\text { bangku }\end{array}$ & $\begin{array}{l}\text { Rasionalitas } \\
\text { instrumental }\end{array}$ \\
\hline $\begin{array}{l}\text { Kelompok Sosial / } \\
\text { social group }\end{array}$ & $\begin{array}{l}\text { Dibuat oleh } \\
\text { masing-masing } \\
\text { toke bangku. }\end{array}$ & $\begin{array}{l}\text { Tertutup dan } \\
\text { dibangun oleh } \\
\text { toke bangku }\end{array}$ & $\begin{array}{l}\text { Konsinyasi dengan } \\
\text { kelompok tertentu }\end{array}$ & $\begin{array}{l}\text { Rasionalitas } \\
\text { instrumental }\end{array}$ \\
\hline $\begin{array}{l}\text { Peran sosial / } \\
\text { social role }\end{array}$ & $\begin{array}{l}\text { Toke bangku } \\
\text { berperan menjaga } \\
\text { kehilangan ikan }\end{array}$ & $\begin{array}{l}\text { Toke bangku } \\
\text { menjamin } \\
\text { menetapkan } \\
\text { harga ikan }\end{array}$ & $\begin{array}{l}\text { Toke bangku yang } \\
\text { menentukan sistim } \\
\text { transaksi }\end{array}$ & $\begin{array}{l}\text { Rasionalitas } \\
\text { instrumental }\end{array}$ \\
\hline $\begin{array}{l}\text { Institusi sosial / } \\
\text { social institution }\end{array}$ & $\begin{array}{l}\text { Tersedia aturan } \\
\text { positif \& belum } \\
\text { diadopsi pelaku } \\
\text { usaha }\end{array}$ & $\begin{array}{l}\text { Tersedia aturan } \\
\text { positif \& belum } \\
\text { diadopsi pelaku } \\
\text { usaha }\end{array}$ & $\begin{array}{l}\text { Tersedia aturan } \\
\text { positif yang sesuai } \\
\text { dengan aturan }\end{array}$ & $\begin{array}{l}\text { Rasionalitas } \\
\text { instrumental }\end{array}$ \\
\hline
\end{tabular}

Sumber : Diskusi FGD (Oktober, 2018) / source: FGD discussion (October, 2018).

Keterangan : 1). Tindakan sosial menurut klasifikasi Weber (1964) / Remark: ${ }^{1}$ Social action based on Weber (1964) classification.

Peran sosial toke bangku dalam tindakan sosial rasional instrumental motifnya menjamin ikan yang dikirim mendapat harga yang baik dan tidak menyusut jumlahnya. Pada penjualan ikan toke bangku menjadi penghubung antara pedagang dipasar tujuan dengan pemilik ikan. Pada kasus ini toke bangku mengambil manfaat dengan memainkan harga. Hukum adat laot tidak mengatur sistim distribusi dan pemasaran ikan. Aturan dan norma yang ada mengikuti pasar dan aturan yang dibuat pemerintah, seperti surat karantina ikan. Surat karantina ikan, jarang dilengkapi nelayan karena terbatasnya tenaga yang memantau aktivitas yang dilakukan toke bangku. 


\section{TINDAKAN SOSIAL MEMFUNGSIKAN SKPT SABANG}

Tindakan sosial pada Tabel 1, Tabel 2 dan Tabel 3 , belum mendorong berfungsinya SKPT Sabang. Hal ini terjadi karena fokus SKPT Sabang masih dalam tahap membangun infrastruktur, pembentukan kelembagaan pengelola SKPT, pengembangan ekonomi dan bisnis, serta pemanfaatan sumberdaya perikanan.

Tindakan sosial rasional instrumental (berorientasi bisnis, memasok ikan bermutu dengan pengelola profesional) harus dibangun Pemerintah Pusat (Kementerian Kelautan dan Perikanan). Apalagi kementerian tersebut telah mengeluarkan Kepmen Kelautan dan Perikanan No: 111/Men-SJ/KP. 444/VIII/ 2018 yang menugaskan pegawai Ditjen Perikanan Tangkap dan Ditjen Perikanan Budidaya untuk mengelola SKPT. Namun, Kepmen KP No. 111/MenSJ/KP.444/ VIII/ 2018 menjadikan Dinas Kelautan dan Perikanan Provinsi Aceh dan Kota Sabang tidak aktif memikirkan perkembangan SKPT le Meulee di Sabang, akibatnya serah terima fasilitas SKPT dari Dinas Perikanan Kota Sabang ke Dinas Kelautan dan Perikanan Provinsi Aceh belum diwujudkan.

Dengan demikian, tindakan sosial Pemerintah Pusat diperlukan untuk mendorong perubahan sosial pada masyarakat perikanan di Sabang, seperti perubahan:

1. Budaya melaut one day fishing. Budaya ini dapat diubah melalui perbaikan penguasaan armada perikanan dari $<3$ GT menjadi $>10 \mathrm{GT}$. Penguasaan armada perikanan $>10$ GT akan menambah hari melaut, memerlukan dermaga bongkar ikan, palka ikan serta es untuk menjaga kualitas ikan. Selain itu, tindakan sosial rasional instrumental ini menjadi bagian yang mendorong pengusaha menyiapkan kapal angkut berpalka dan truk berpendingin dalam mendistribusikan ikan.

2. Perubahan budaya di atas, akan meningkatkan permintaan nahkoda (pawang) trampil, dan toke bangku tidak lagi mencari pasar, tetapi menjadi agen penjualan ikan yang dicari pembeli dan diperlukan nelayan.

3. Perubahan tersebut harus dimanfaatkan SKPT Sabang membangun sosial group dengan menghimpun toke-toke bangku dengan sistim insentif agar beroperasi di SKPT. Sosial group ini sangat efektif, karena toke bangku telah menjadi agen penjual ikan di SKPT dan tidak merusak tatanan kelompok sosial yang telah dibuat toke bangku itu.

4. Peran sosial toke bangku menjadi agen penjual ikan di SKPT Sabang, mendorong beberapa bisnis (seperti perbankan, SPDN, es) membuka usaha di SKPT dengan motif memanfaatkan potensi yang berkembang di SKPT.

5. Institusi sosial pendorong perubahan dengan instrument yang baku. Landasan utama institusi sosial itu adalah regulasi dari pemerintah dan hukum adat laot sebagai pelengkap, apalagi SKPT berorientasi ekspor.

Jika perubahan sosial itu dapat diwujudkan Pemerintah Pusat, maka peluang berfungsinya SKPT Sabang sangat besar.

\section{KESIMPULAN DAN KEBIJAKAN Kesimpulan}

Tindakan sosial tradisional umum terjadi pada sistim produksi. Pada tindakan sosial tersebut kekuasaan pelaku usaha tidak efektif dan jika pelaku usaha tidak taat aturan akan dikenai sanksi sosial oleh panglima laot. Selain itu, tindakan sosial rasionalitas instrumental kerap terjadi pada kegiatan penanganan ikan hasil tangkapan, distribusi dan pemasaran ikan. Tindakan sosial yang terakhir ini, dilakukan nelayan untuk efisiensi ekonomi, dan dilakukan toke bangku untuk mendapat pasokan ikan. Kekuasaan toke bangku sangat efektif mempengaruhi pelaku usaha lain.

Pada dua tindakan sosial di atas pelaku usaha berupaya menjaga pola relasi agar transaksi tetap berjalan lancar. Aktivitas usaha dilakukan dengan efisiensi ekonomi memanfaatkan kekuasaan yang melekat pada setiap pelaku usaha serta relasi sosial yang terbentuk.

Kesamaan motif tindakan sosial pada kegiatan diatas dapat dijadikan dasar untuk mengorganisasikan pelaku usaha perikanan di Sabang dalam suatu lembaga (organisasi), sehingga menjadi faktor pendorong untuk memfungsikan SKPT Sabang.

\section{Kebijakan}

Perubahan sosial pada bisnis perikanan Sabang untuk memfungsikan SKPT Sabang dilakukan melalui kebijakan:

1. Transformasi $30-40 \%$, dari 648 unit armada perikanan < $3 \mathrm{GT}$ menjadi armada perikanan $>10$ GT selama 5 tahun oleh Pemerintah Pusat. Tindakan sosial ini akan meningkatkan permintaan nahkoda (pawang) trampil dan ABK.

2. Tindakan sosial di atas harus diikuti dengan membangun serta mengoperasikan stasiun pengisi BBM - Solar Packed Dealer Nelayan di dalam 
SKPT Sabang oleh Pemerintah Pusat. Insentif pelayanan BBM harus diutamakan untuk nelayan yang membongkar ikan di SKPT. Mendorong kelembagaan pengelola SKPT Sabang kreatif membuat aturan sehingga berbagai fasilitas SKPT dapat dioperasikan, terutama: tempat pelelangan ikan, ice flake, cold storage, kolam tambat labuh.

3. Tindakan sosial pengelola SKPT tersebut, diperlukan agar tumbuh motif ekonomi pada pelaku usaha lain memanfaatkan peluang menyediakan: usaha pengangkut ikan berpendingin, lembaga keuangan serta fasilitas perdagangan ikan.

4. Memobilisasi pengelola SKPT bergerak aktif mendorong perubahan sosial dalam SKPT, mengakomodasi kebutuhan armada perikanan, dan bernegosiasi dengan toke bangku agar beroperasi sebagai agen penjualan ikan di dalam SKPT Sabang.

\section{PERSANTUNAN}

Terima kasih kepada Plt. Kepala Balai Besar Riset Sosial Ekonomi Kelautan dan Perikanan dan Kabid Tata Operasional Balai Besar Riset Sosial Ekonomi Kelautan dan Perikanan atas kesempatan yang diberikan untuk melakukan kajian di SKPT Sabang pada Oktober 2018. Subtansi tulisan ini semakin terarah karena peran Dr. Rilus A. Kinseng (Departemen Sains Komunikasi dan Pengembangan Masyarakat - FEMA - IPB).

\section{DAFTAR PUSTAKA}

Anonim. (1992). Keputusan Pertemuan Panglima Laot / Musyawarah Panglima Laot Se Provinsi Daerah Istimewa Aceh. Tanggal 23 - 25 Januari 1992, di Langsa Aceh Timur (p. 66). Dinas Perikanan Provinsi Daerah Istimewa Aceh.

Berger, P.L., \& T. Luckmann. (1991). The Social Construction of Reality A Treatise in the Sociology of Knowledge. (p. 125). Penguin Books. Printed in England by Clays Ltd, St Ives plc.

BPS Kota Sabang. (2018). Sabang dalam Angka 2017. (p. 270). Badan Pusat Statistik Sabang.

Budowski, M., \& R. Tillmann. (2013). Social stratification. in A.C. Michalos (eds). Encyclopedia of quality of life research. (p. 4). Springer Science Business Media Dordrecht.

Damsar \& Indrayani. (2013). Sosiologi ekonomi. (p. 317). Jakarta. Kencana Prenada Media.
Ditjen Perikanan Budidaya. (2016). Bisnis plan Sentra Kelautan dan Perikanan Terpadu, Kota Sabang. (p. 135). Jakarta - KKP.

Ditjen Perencanaan Ruang Laut. (2017). Master plan Sentra Kelautan dan Perikanan Terpadu, Kota Sabang. (p 189). Jakarta - KKP.

de Lange, G. (2017). Understand prescriptive analytics in 20 minutes. (pp. 16). AIMMS.

Connecting Business \& Optimization.

Ferris, Kerry., \& J. Stein. (2010). The real world an introduction to sociology. $2^{\text {nd }}$ ed. (p. 98). New York: W.W. Norton.

Granovetter, M. (1985). Economic action and social structure: The Problem of Embeddedness. The University of Chicago Press. American Journal of Sociology. (91), 3, 481-510.

Granovetter, M. (1995). The economic sociology of firm and entrepreneur, in A. Portes (ed.). The Economic Sociology of Immigration. (p. 213). New York: Russel Sage Foundation.

Huisman, D.O. (2015). To what extend do predictive, descriptive and prescriptive supply chain analytics affect organization performance?. $5^{\text {th }}$ IBA thesis conference 2 July 2015. (p. 8). The Faculty of Behavioral, Management and Social Sciences. Univ. Twente. Netherland

Heaney, B. (2015). Supply chain intelligence: descriptive, Prescriptive and Predictive Optimization. (p. 17). ABERDEEN GROUP. A Harte Hank Company.

Hodgson, G.M. (1998). The approach of institutional economics. Journal of Economic Literature. (36)1, 166-192.Download from: http://links.jstor.org/ sici?sici $=00220515 \% 28199803 \% 2936 \%$ 3A1\%3C166\% 3ATAOIE\%3E2.0.CO\%3 B2-Q

Johnson, D.P. (1994). Teori sosiologi klasik dan modern - jilid 2. (p. 96). Jakarta. Gramedia Pustaka Utama.

Jones, P., Bradbury, L., \& Boutilleir, S.L. (2016). Pengantar teori-teori sosial. (p. 86). Jakarta, Yayasan Pustaka Obor Indonesia.

Jackie, O., P. Tanpichai., \& A. Jai-aree. (2018). Construction of social space in Thai hill tribe ethnic 
groups in Kamphaeng Phet province. Kasetsart Journal of Social Sciences. (30), 1- 7 DOI: https:/ /doi.org/10.1016/j.kjss.2018.07.019

Kepmen KP No. 51/KEPMEN-KP/2016. (2016). Penetapan lokasi pembangunan sentra kelautan dan perikanan terpadu di Pulau-Pulau Kecil dan Kawasan Perbatasan. Biro Hukum, KKP

Kepmen KP No. 50/KEPMEN-KP/2017. (2017). Estimasi potensi, jumlah tangkapan yang diperbolehkan, dan tingkat pemanfaatan sumber daya ikan di wilayah pengelolaan perikanan Negara Republik Indonesia. Biro Hukum, KKP.

Lim, B.T.H., \& M. Loosemore. (2016). How socially responsible is construction business in Australia and New Zealand?. Procedia Engineering 180 (p. 531-540). International High- Performance Built Environment Conference - A Sustainable Built Environment Conference 2016 Series (SBE16), iHBE.

Martono, N. (2014). Sosiologi perubahan sosial persfektif klasik, moderen. Posmoderen dan poskolonial. (p. 419). Jakarta Rajagrafindo Persada.

Matuschke, I. (2008). Evaluating the impact of social networks in rural innovation systems: An overview. The International Food Policy Research Institute (IFPRI), Washington, DC. (p. 26). IFPRI Discussion Paper 00816.

Mooney, L. A., Knox, D., \& Schacht, C. (2000). Understanding Social Problems. 2nd ed. (p. 285). Cincinnati, $\mathrm{OH}$ : Wadsworth.

Oyedokun, G. E. (2016). Management Thoughts: The Review of Social Action Theory. Article in SSRN Electronic Journal · January 2016 DOI: 10.2139/ ssrn.2912274. down load from: https:// www.researchgate.net/publication/317995900. 10 March 2018.

Pretty, J. (1995). Regenerative agriculture: policy and practice for sustainability and self reliance. London, Earthscan. Dalam R. Ramirez (eds) 1995. Participatory learning and communication approaches for managing pluralism. http:// www.fao.org/document/show_cdr.asp? url_file $=$ DOCREP/W8827E/w8827e08.htm. down load 10 Oct 1018 .

Pinker, S. (1998). How the mind works. (p. 660). Penguin Books. London
Priya, R. (2013). Weber 4 ideal types of social action. http://www.yourarticle library .com /sociology/ types-of-social-action-according-to-max-weber/ 43755/

Parsons, T. (1951). The social system. (p. 86). New York. Free Press.

Poloma, M.M. (2007). Sosiologi kontemporer. (p. 98). Jakarta. RadjaGrafindo Persada.

Ravikumar, T., N. Ram., S. Dam-Roy., P. Krishnan., Grinson-George., M. Sankaran, V. Sachithanandam. (2015). Traditional usages of ichthyotoxic plant Barringtonia asiatica (L.) Kurz. by the Nicobari tribes. Journal of Marine and Island Cultures (4), 76-80.

Ravikumar, T., N. Ram., P. Krishnan., R. K. Sankar., V. Sachithanandam., S. D. Roy. (2016). Subsistence fishing methods of Nicobari tribes using traditional knowledge. Journal of Marine and Island Cultures (5), 79-87.DOI:https://doi.org/ 10.1016/j.imic. 2016.05.002

Rohmaida, F.N., \& Utami, D. (2016). Tindakan sosial penggunaan uang "ganti rugi" petani tambak pasca alih fungsi lahan di Desa Manyar Sidorukun Kecamatan Manyar Kabupaten Gresik. Paradigma. (4)3, 1-12.

Riss, I. (2016). Typology of social actions based on the living system theory. Download from https:// www.researchgate.net/publication/319330486. (12 January 2019).

Samuels, W.J. (1995). The present state of institutional economics. Cambridge Journal of Economics (19), 569-590

Sanderson, S.K. (2010). Makro sosiologi: sebuah pendekatan terhadap realitas sosial. (p. 105). PT RajaGrafindo Persada. Jakarta.

Supraja, M. (2012). Alfred Schutz: Rekonstruksi Teori Tindakan Max Weber. Jurnal Pemikiran Sosiologi. (1) 2, 81-90.

Thomson, K. (2017). Max weber's social action theory. Down load from https://revisesociology .com /2017/ 01/26/max-webers-social-action-theory/. (3 Feb. 2019).

Trueman, C.N. (2015). Social action theory. (p. 6). Download from http:// historylearning site.co.uk. (5 April 2019). 
Weber, M. (1964). The theory of social and economic organization. (p. 94). The Free Press. A Division of Simon \& Schuster Inc. New York.

Wyatt-Nichol, H., S. Brown., \& W. Haynes. (2011). Social class and socioeconomic status: Relevance and Inclusion in MPA-MPP Programs. Journal of Public Affairs Education. (17)2,187-208.Download from http://www.naspaa.org/JPAEMessenger/ index_2011spring.asp
Zulham, A., Subaryono., \& Anggawangsa, R. F. (2017). Rekomendasi pengembangan perikanan tangkap di natuna dan sekitarnya. (p.66). Depok. PT RajaGrafindo Persada.

Zulham, A. (2018). Penilaian sosial dalam membangun entitas bisnis perikanan pada SKPT Selat Lampa, Natuna. J. Kebijakan Sosial Ekonomi Kelautan dan Perikanan. (8), 1, 77 - 90. DOI: http:// dx.doi.org/10.15578/jksekp.v8i1.7102 